\title{
A model free dissolved oxygen controller for industry effluent using hybrid variables measuring technique
}

\author{
P. Kingston Stanley ${ }^{1}$, Sanjeevi Gandhi A. ${ }^{2}$, D. Abraham Chandy ${ }^{3}$ \\ ${ }^{1,3}$ Karunya Institute of Technology and Sciences, India \\ ${ }^{2}$ Karpagam College of Engineering, India
}

\section{Article Info \\ Article history: \\ Received Sep 19, 2018 \\ Revised Mar 25, 2019 \\ Accepted Apr 15, 2019}

\section{Keywords:}

Dissolved oxygen

Heteropolymer - formazin

LabVIEW

Turbidity

Waste water

\begin{abstract}
The present scenario of the world relays on water scarcity, enormous amount of water is needed for people but the world has pollution which makes a great effect. Water is polluted due to various reasons such as industrial waste, sewage, and global warming and oil pollution and mainly polluted due to industrial effluent waste water. The main objective of this paper is to control the dissolved oxygen of the industrial waste water by measuring turbidity and dissolved oxygen (DO). Turbidity is measured through the intensity of the light through the medium in Nephelometric unit (NTU) and dissolved oxygen is measured in PPM through amperometic electrode method. The controller is designed to improve the quality of the effluent water through the aeration process. The very low concentration of dissolved oxygen (DO) level is too harmful to the aquatic ecosystem and it pollutes the water to the maximum extent. This measurement method of turbidity has an enhanced idea which processed with the software and it is monitored. The controller is designed as such with the condition of inverse proportionality of water turbidity and dissolved oxygen, which contributes an additive advantage to the concept design.
\end{abstract}

Copyright (C) 2019 Institute of Advanced Engineering and Science. All rights reserved.

\author{
Corresponding Author: \\ P. Kingston Stanley, \\ Karunya Institute of Technology and Sciences, \\ Karunya Nagar, Coimbatore, Tamil Nadu 641114, India. \\ Email: kingstonstanley@karunya.edu
}

\section{INTRODUCTION}

The dissolved oxygen is very important factor in measuring the water quality. The dissolved oxygen level in the water should be moderate for the aquatic life in the water. The presence of dissolved oxygen is must for the aquatic level but the range should be in some certain level. Frequently varying amount of dissolved oxygen in the water level also harm the aquatic life and pollute the water nominal rate should be processed. Lower the amount of dissolved oxygen also causes water pollution. The cloudy appearance of the water caused the presence of suspended and colloidal matter. In the waterworks field, a turbidity measurement is used to indicate the clarity of water. An improvised model predictive control is being added to already develop PI control which utilizes dissolved oxygen concentration and the air pressure of the aeration system. [1]. Control of the DO concentration in the Benchmark Simulation Model No. 1 (BSM 1) was done using the proposed T-S fuzzy neural network. A fast and efficient real time control of DO concentration in the waste treatment plant is observed by adjusting the learning rate which in turn increases the convergence rate of the system [2]. In any waste water management system oxygen is a key variable that needs to be controlled beside other variables for the simulation prove that the expected level of DO for MPC can be achieved [3]. An increased accuracy is possible when the weak scattered light is measured using a single photon avalanche diode (SPAD) a resolution of 0.1 NTU can be measured within 1s [4]. The Simulations results in provided segment as well as comparison results against a well-known Lyapunov based controller and a classical PID controller [5]. The Nephelometric turbidity values ranges from 40 to 400 NTU. 
In the activated sludge waste water treatment plant DO is a crucial factor which determines how efficiently the biological processes are taking place. Improvisation of the Direct Model Reference Adaptive control (DMRAC) is relation to DO tracking for the Sequencing Batch Reactor (SBR) is put forward [6]. The first step was to identify dissolved oxygen control loop at various operating points. By using simulation the gain scheduling control strategy of DO concentration was tested; an experimentally pilot plant is also presented in this paper [7]. The successful control strategies usually employ PI control for industry based applications. Effectiveness of GS-PI and MNC control methods are displayed using simulations performed on nonlinear model [8]. The process of sewage treatment is a convoluted biochemical process. The simulation results point out a better response speed, reduced overshoot and also a reduced static error is observed [9]. Waste Water treatment plant in general is a complicated, multivariable, time depended and enormous industrial system which is nonlinear. Air/Oxygen for the aerated tanks is obtained through the aeration system (blowers, pipes, diffusers). Investigation is being carried out for the nonlinear fuzzy PI control system [10]. The outcome of this study is the development of a PC based virtual (VI) system using LABVIEW, which automatically monitors and controls the Dissolved Oxygen concentration (DO). This drastically reduces business costs in terms of automation required and has higher effectiveness with lower electricity consumption [11]. The optimal set-point of dissolved oxygen affects both the batch time and energy savings. PC-based virtual instrument (VI) system using LabVIEW, which can monitor and control the dissolved oxygen (DO) concentration in an automated manner and the quality of DO is been analyzed [12]. The controllers are validated by simulation using real data sets and an ASM2d model of the biological reactor. On the consolatory aspect, three model predictive controllers (MPCs) are designed, tested and the results are compared with a PI controller. A well-established simulation benchmark is used as a test bench for this study [13]. Fuzzy logic based controlled was designed for aeration process [14]. The batch time and the energy savings are affected by the optimal set point of the parameter dissolved oxygen $[15,16]$. An investigation is being carried out for the nonlinear model predictive controller and direct reference adaptive controller. Validation of the controller is done using simulated real data sets and an ASM2d model of a biological reactor [17-21]. Various model predictive controllers for dissolved oxygen in an activated sludge wastewater treatment plant (WWTP) are being discussed. This paper proposes a new system that measures turbidity and dissolved oxygen for designing an efficient DO controller. Because turbidity is inversely proportional to DO value of water. Therefore, measuring both variables and designing a controller makes the system output response better. This paper also contributes an enhanced approach of model free control for dissolved oxygen (DO).

\section{METHODOLOGY}

\subsection{Turbidity measurement}

The turbidity values are measured in NTU (Nephelometric Unit). Earlier concepts measured turbidity based on the amount of light scattered through the sample medium. Instead of measuring scattered rays of light, the other method is suggested to measure the intensity of light transmitted through the sample. It consists of a light source, which is a LASER emitting diode at a wavelength of $670 \mathrm{~nm}$. The light from the LASER passes through the turbid solution and falls on a photo detector. The output signal from the photo detector is given as analog input to the embedded system, where it is processed and the given analog input is calibrated Nephelometric turbidity unit and which is reported in Table 1. This turbidity measurement values are compared with standard turbidity measuring instrument. Figure 1 shows the process to measure the turbidity. Turbidity of the sample considered is inversely proportional to dissolved oxygen concentration. This turbidity measurement helps in designing efficient controller. Different known samples were prepared to calibrate turbidity meter.

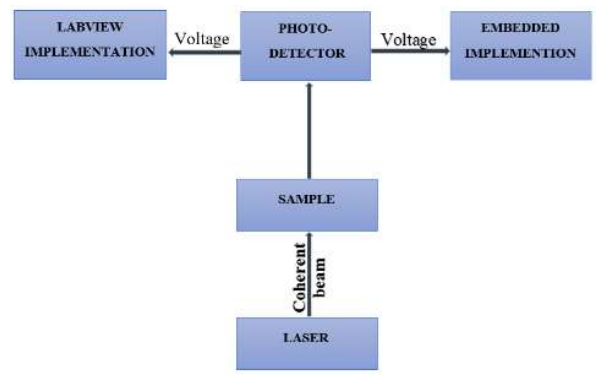

Figure 1. Turbidity measurement process

Int. J. of Adv. in Appl. Sci. Vol. 7, No. 2, June 2019: 157 - 163 
Table 1. Min and max output voltage value

\begin{tabular}{cc}
\hline $\begin{array}{c}\text { SOLUTION } \\
\text { (NTU) }\end{array}$ & $\begin{array}{c}\text { VOLTAGE } \\
\text { (volts) }\end{array}$ \\
\hline 40 & 0.3 \\
400 & 4.6 \\
\hline
\end{tabular}

\subsection{Solution preparation}

In order to calibrate the turbidity measuring system the standard formazin (heterocyclic polymer) is prepared by three step processes [20].

Step 1 - Preparation of solution A: Dissolving $1 \mathrm{gm}$ of Hydrazine sulphates in $50 \mathrm{ml}$ of water and dilute to $100 \mathrm{ml}$ by using distilled water.

Step 2 - Preparation of solution B: Dissolving $10 \mathrm{gm}$ of Hexamine in $50 \mathrm{ml}$ of distilled water and dilute to $100 \mathrm{ml}$ in distilled water.

Step 3 - Formazin Preparation: Take $5 \mathrm{ml}$ of solution A and it mix with $5 \mathrm{ml}$ of solution B and allow to stand 24 hours at $25^{\circ} \mathrm{C}$ to $30^{\circ} \mathrm{C}$ temperature and dilute to $100 \mathrm{ml}$ of distill water to attain a standard formazin turbid solution of $400 \mathrm{NTU}$. The stock samples were analyzed and tested to calibrate the measuring system. The chemical reactions are shown in Figure 2.

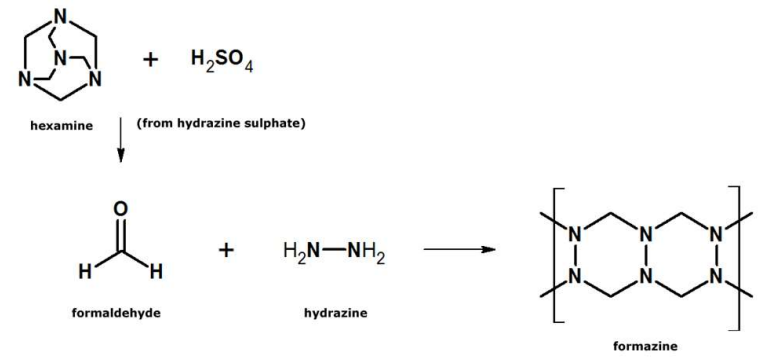

Figure 2. Three steps of solution preparation

\subsection{Dissolved oxygen control}

Based on literature survey most of the industry effluent waste waters have very low dissolved oxygen. Figure 3 shows about the overall block diagram of Dissolved oxygen aeration process control in effluent waste water.

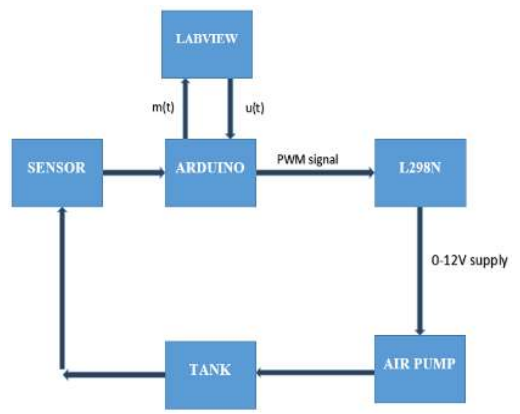

Figure 3. Block diagram of dissolved oxygen aeration process control

Dissolved oxygen sensor works based on the amperometric method. Current flow in between the electrodes is proportional to the dissolved oxygen concentration in the water. Analog output from dissolved oxygen sensor is interfaced with Arduino. To acquire the data using LabVIEW, there is an additional Arduino tool installed. The analog signal from the dissolved oxygen sensor is given to the Arduino and it is directly read through LabVIEW without any specialized data acquisition hardware. The air pump is used as actuator device to adjust the DO level in the waste water by varying the input voltage of the pump range from $0-12 \mathrm{v}$.

A model free dissolved oxygen controller for industry effluent using hybrid ... (P. Kingston Stanley) 
Figure 4 epics the variation in the DO concentration during the aeration process by varying the pump voltage in range of $2 \mathrm{~V}, 4 \mathrm{~V}$ and $10 \mathrm{~V}$. By changing the pump input voltage, data's are collected and used for designing gain values of PID controller.

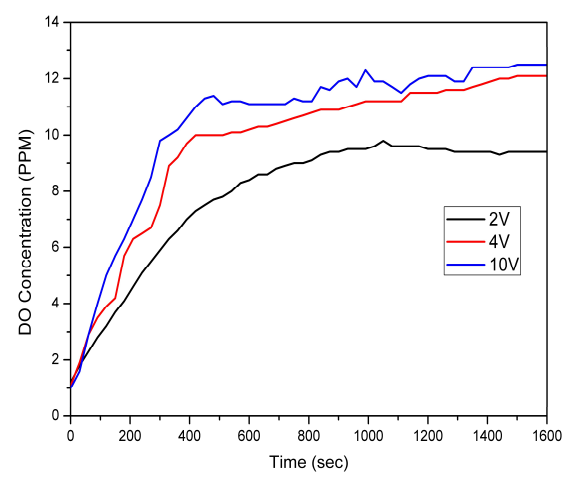

Figure 4. Input voltage to pump

\section{RESULTS AND DISCUSSION}

\subsection{Experimental results for turbidity measurement}

The results have obtained from the turbidity sensor using the known samples which were prepared. The analog voltage from the turbidity sensor (L14G1) is fed as variable input through the DAQ in LabVIEW to the formula node. The formula node computes the turbidity value and which is displayed on the front panel. The results were shown in embedded LED display as well as in LabVIEW. Using formula node, DAQ and While loop in LabVIEW is used to convert the LED voltage (0-5V) output to Nephelometric (40-400 NTU) Unit. Figure 5 shows the LabVIEW design for calibrating the voltage value from phototransistor into NTU. The output voltage for various values of 10 samples with different turbidity ranges are shown in Figure 6.

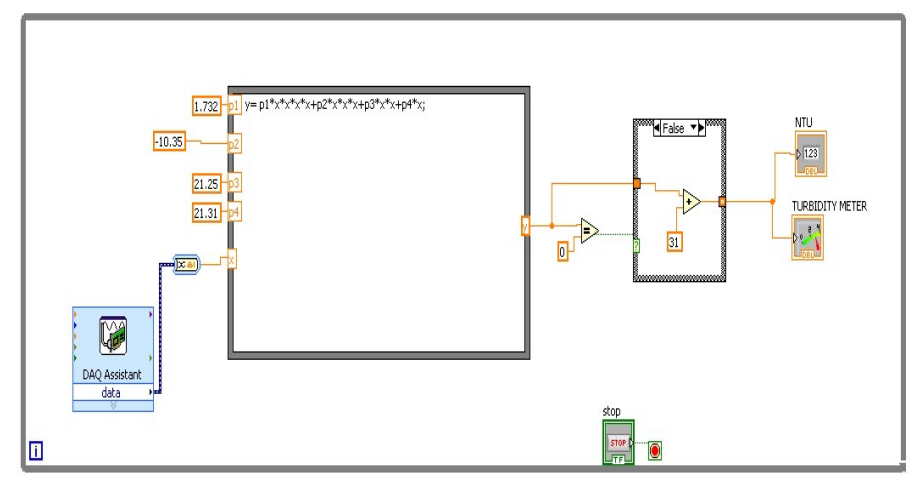

Figure 5. LabVIEW for converting voltage to NTU

Higher order polynomial equation can improve the curve fitting relation between the input (voltage) and the output (turbidity). Therefore 4th degree linear polynomial formula which is used to convert voltage into turbidity as follows:

$$
\begin{aligned}
& \mathrm{Y}=\mathrm{q} 1 * \mathrm{x}^{\wedge} 4+\mathrm{q} 2 * \mathrm{x}^{\wedge} 3+\mathrm{q} 3 * \mathrm{x}^{\wedge} 2+\mathrm{q} 4 * \mathrm{x}+\mathrm{q} 5 \\
& \mathrm{q} 1=1.732 \\
& \mathrm{q} 2=-10.35 \\
& \mathrm{q} 3=21.25 \\
& \mathrm{q} 4=21.31 \\
& \mathrm{q} 5=31
\end{aligned}
$$

Int. J. of Adv. in Appl. Sci. Vol. 7, No. 2, June 2019: 157 - 163 


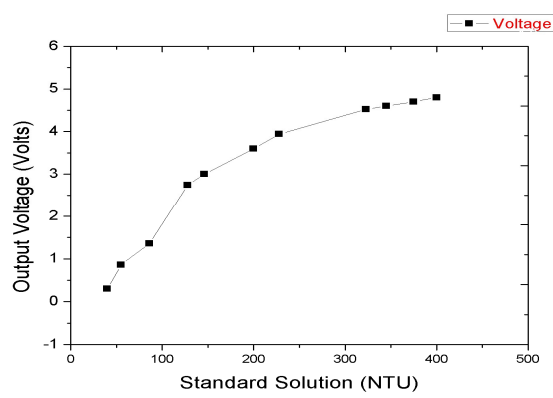

Figure 6. Samples solution vs output voltage

\subsection{PID controller design for DO}

Thus the real time PID controller is implemented in LabVIEW. The set point of 5 PPM is taken to the three samples, the PID controls the process, the steady state is obtained at various load changes of each samples. The PID Controller designed using LabVIEW, is tuned using Ziegler Nicholes method and the gain is changed by noting the response of the system.

Figure 7 shows the design of LabVIEW program to control DO level. Design of controllers are always different in real time implementation. Therefore PID controller gain values are selected from trial and error method also and its suits for DO concentration set point tracking. Proportional \& Integral controllers are used frequently in automation industry, especially when quickness of the response is not a matter. A control without Derivative mode is used when fast response of the system is not required and great disturbances and noise are existing during operation of the process. As the aeration process makes the DO to change quickly, Proportional, Integral and derivative gain very much need for this process.

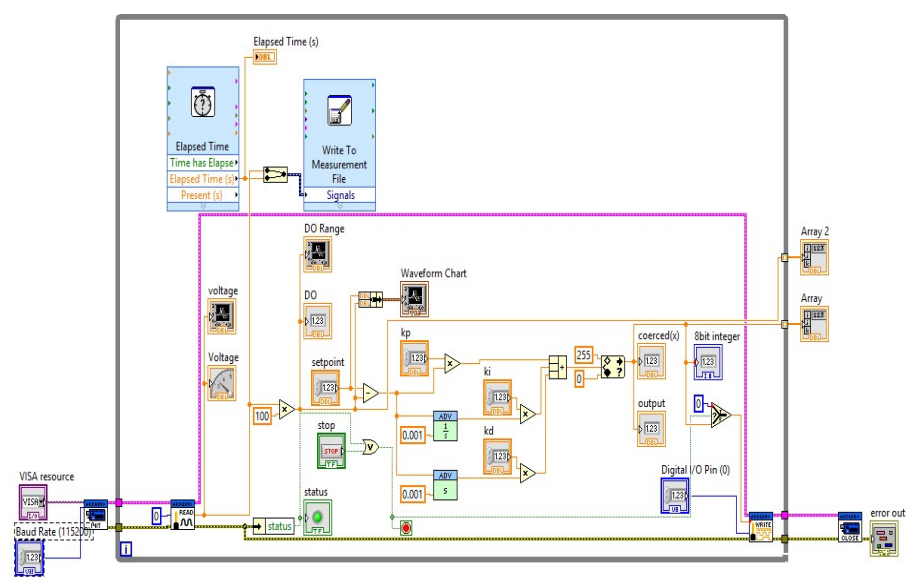

Figure 7. LabVIEW program to control DO level using PID controller

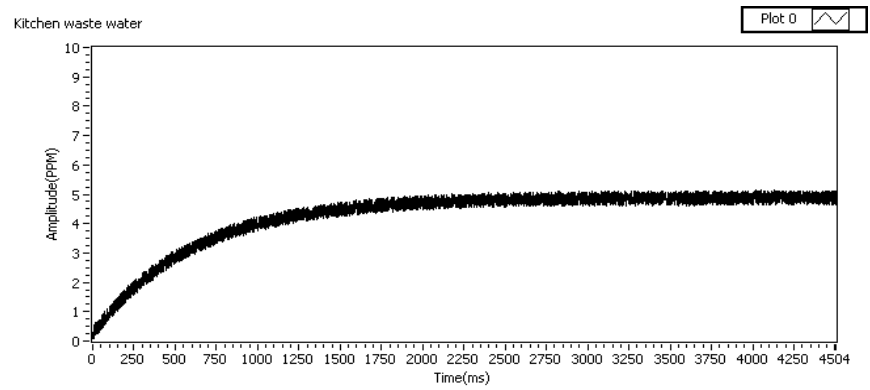

Figure 8. PID controller response for domestic wastewater 


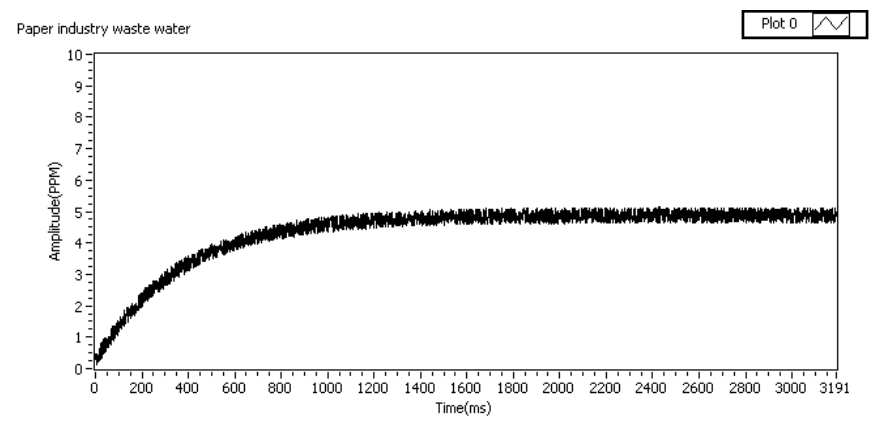

Figure 9. PID controller response for paper industry wastewater

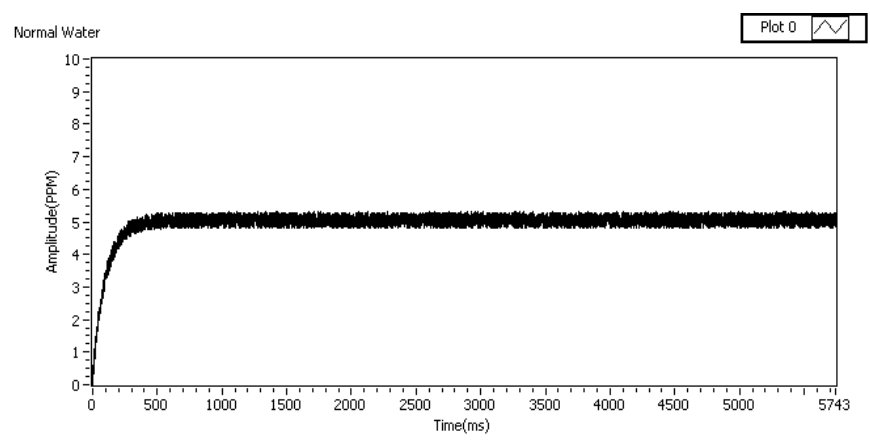

Figure 10. PID controller response for normal water

Figure 8 demonstrates the DO Control in domestic waste water. The waste water must have a minimum of 5 PPM level of DO concentration as per the literature survey. Therefore set point of 5PPM was taken to control the concentration of DO. Figure 9 indicates the DO control for paper industry waste water, the PID controller was able to achieve to the set point value of 5 PPM within 1000 milli-seconds. These experiments are tested with 30L water. The DO control for normal water is shown in Figure 10. The comparing all these three results, normal water reacts quickly to reach the set point of 5 PPM. And these experiments were performed multiple times with fresh waters in the setup. The designed controller responses shows that the controller is able to track DO concentration effectively using hybrid variables rather than measuring single variable based DO control. Through this hybrid variables based automation process, much amount of energy can be saved.

\section{CONCLUSION}

In industrial effluent and domestic waste water have measured in terms of turbidity and DO concentration. The turbidity sensor and DO sensor were calibrated with help of standard solution. The designed turbidity measurement is another method which is useful to measure colloidal particles of water in fields with a lesser conceptual cost aspect. Many phototransistors were used to improve the sensitivity of measuring turbidity values. The model free controller is designed to control the DO concentration effectively using both variables namely turbidity and DO concentration. The controlling of DO level concentration reduces the risk of polluting the land and can cut down many harmful factors too. The output responses of PID controllers with DO concentration level for domestic waste water; industrial effluent and drinking water were shown. From the responses it was understood the controller is effectively controlling the DO concentration without any overshoot and under shoot. The real time PID controller was successfully implemented in the pilot plant. The adaptive controller will be proposed to reduce the settling time of the process.

Int. J. of Adv. in Appl. Sci. Vol. 7, No. 2, June 2019: 157 - 163 


\section{REFERENCES}

[1] Gabriel Harja, Grigore Vlad, and Ioan Nascu, "MPC advanced control of dissolved oxygen in an activated sludge wastewater treatment plant," IEEE International Conference on Automation, Quality and Testing, Robotics, 2016. [Online]. Available: https://ieeexplore.ieee.org/document/7501329/.

[2] Wen-Tao Fu, Jun-Fei Qiao, Gai-Tang Han,and Xi Meng, "Dissolved oxygen control system based on the T-S fuzzy neural network," IEEE International Conference Neural Networks, 2015. [Online]. Available: https://ieeexplore.ieee.org/document/7280506/.

[3] Xiaoxin Liu, Yuanwei Jing, Tao Ren, and Siying Zhang, "Model predictive control application in dissolved oxygen control," IEEE Chinese Control and Decision Conference, 2015. [Online]. Avalaible: https://ieeexplore.ieee.org/document/7162095/.

[4] Huanqin Wang, Yixin Yang, Zhe Huang, and Huaqiao Gui, "Instrument for Real-Time Measurement of Low Turbidity by Using Time-Correlated Single Photon Counting Technique," IEEE Transactions on Instrumentation and Measurement, vol. 64(4), pp. 1075-1083, 2015.

[5] Alex Alzate, Adriana Amicarelli, Lina Gómez, and Fernando di Sciascio, "Model based predictive strategy for dissolved oxygen control applied to a batch bioprocess," IEEE - Workshop Information Processing and Control, 2015.

[6] Piotr Hirsch, Robert Piotrowski, and Kazimierz Duzinkiewicz, "Two-step model based adaptive controller for Dissolved Oxygen control in Sequencing Wastewater Batch Reactor," International Conference on Methods and Models in Automation and Robotics, 2015.

[7] Ciprian Vlad, Sergiu Caraman, Daniela Carp, Viorel Mînzu, and Marian Barbu, "Gain Scheduling control of dissolved oxygen concentration in a wastewater treatment process," Mediterranean Conference Control \& Automatio,. 2012.

[8] C. Vlad, M. Sbarciog, M. Barbu, S. Caraman, and A. Vande, "Wouwer Indirect Control of Substrate Concentration for a Wastewater Treatment Process by Dissolved Oxygen Tracking," Journal of control engineering and applied informatics, vol. 14(1), pp. 37-47, 2012.

[9] Minghe Li, Jingen Peng, and Jian Wang, "Study on Smith-self-adaptive fuzzy PID controller in dissolved oxygen control of sewage treatment," IEEE Conference Industrial Electronics and Applications, 2012.

[10] Zawadzki, R. Piotrowski, "Nonlinear fuzzy control of the dissolved oxygen in activated sludge processes," IEEE Conference Emerging Technologies \& Factory Automation, 2012.

[11] Hsiung Cheng Lin, Liang-Tsung Huang, Lien-Fu Lai, and Yin-Fan Chi, "A remote automated system for a case study of dissolved oxygen monitoring and control," IEEE International Symposium on Industrial Electronics, 2009.

[12] Baiqing Zhou, Juan Liu, and Lu Li, "Evaluation Method for Performance of Reverse Osmosis Antiscalants Based on the Turbidity," International Conference on Electrical and Control Engineering, 2010.

[13] Jun-dong Wang, Pei-yan Li, Yong-ming Zhang, and Wei-gui Qi, "River Water Turbidity Forecasting Based on Phase Space Reconstruction and Support Vector Regression," Intelligent Computation Technology and Automation (ICICTA), International Conference, 2010.

[14] J. Ferrer, M. A. Rodrigo., A. Seco, and J.M. Penya-roja, "Energy saving in the aeration process by fuzzy logic control," Water Science and Technology, vol. 38(3), pp. 209-217, 2017.

[15] Ruey-Fang Yu, Cheng-Nan Chang, and Wan-Yuan Cheng, "Applying real time control to enhance the performance of nitrogen removal in the continuous flow SBR system," Water science and Technology, vol. 38(3), pp. 271-280, 1998.

[16] Young-Hwang Kim, Chang Kyoo Yoo, and In-Beum Lee, "Optimization of biological nutrient removal in a SBR using simulation -based iterative dynamic programming," Chemical Engineering Journal, vol. 139(1), pp. 11-19, 2008.

[17] W. Chotkowski, M. A. Brdys, and K. Konarczak, "Dissolved oxygen control for activated sludge processes," International Journal of Systems Science, vol. 36(12), pp. 727-736, 2005.

[18] Reza Loloee, Per A. Askeland, and Ruby N., "Ghosh Dissolved Oxygen Sensing in a Flow Stream using Molybdenum Chloride Optical Indicators," IEEE Sensors, 2007.

[19] Sanchez and M. R. Katebi, "Predictive control of dissolved oxygen in an activated sludge wastewater treatment plant," European Control Conference, 2003.

[20] Budi Srinivasarao, G. Sreenivasan, and Swathi Sharma, "Comparison of Dynamic Stability Response of A SMIB with PI and Fuzzy Controlled DPFC," Indonesian Journal of Electrical Engineering and Informatics, vol. 5(3), pp. 199-206, 2017.

[21] V. Balaji, Dr. L. Rajaji, and Shanthini K., "Comparison Analysis of Model Predictive Controller with Classical PID Controller for $\mathrm{pH}$ Control Process," Indonesian Journal of Electrical Engineering and Informatics, vol. 4(4), pp. 250-255, 2016. 